Article

\title{
Simulation of Standby Efficiency Improvement for a Line Level Control Resonant Converter Based on Solar Power Systems
}

\author{
Ming-Tse Kuo * and Ming-Chang Tsou \\ Department of Electrical Engineering, National Taiwan University of Science and Technology, No. 43, \\ Section 4, Keelung Road, Da'an District, Taipei 106, Taiwan; E-Mail: ming@leadtrend.com.tw \\ * Author to whom correspondence should be addressed; E-Mail: mkuo@mail.ntust.edu.tw; \\ Tel.: +886-2-2730-3288; Fax: +886-2-2737-6699.
}

Academic Editor: Andrés G. Muñoz

Received: 13 September 2014 / Accepted: 22 December 2014 / Published: 5 January 2015

\begin{abstract}
This paper proposes a new scheme to improve the standby efficiency of the high-power half-bridge line level control (LLC) resonant converter. This new circuit is applicable to improving the efficiency of the renewable energy generation system in distributed power systems. The main purpose is to achieve high-efficiency solar and wind power and stable output under different load conditions. In comparison with the traditional one, this novel method can improve standby efficiency at standby. The system characteristics of this proposed method have been analyzed through detailed simulations, which prove its feasibility.
\end{abstract}

Keywords: line level control (LLC) resonant converter; holdup time; standby efficiency; distributed generation (DG)

\section{Introduction}

In most countries, the traditional power-supply system is dominated by large power generators that deliver electricity to each client through the power grid. However, energy supply sources should not rely merely on fuel because of the increasing energy crisis. If a portion of a household's electricity is supplied by way of renewable energy, shortfalls can be covered by electricity companies; when there is surplus renewable energy, it can be fed back into the power grid, adding to the energy supply. Additionally, if most of the households are equipped with recovery apparatus for renewable energy to 
reduce power consumption, the power company can also minimize the amount of fossil fuel required to satisfy the load capacity and thereby control environmental pollution. Small distributed generation (DG) systems can generally be categorized into three types, as shown in Figure 1. The first type is the grid-connection system [1]. The power provided by solar power modules is delivered to the load, and excess electricity can be fed into power grid; when the locally provided power is insufficient, the power grid compensates for the inadequacy. The second type is the stand-alone system [2]. Solar or wind power is often treated as renewable energy resource. For example, solar power can charge batteries for contingent use with excess energy; when the electricity from solar power cannot meet the immediate power demand, batteries back up the power insufficiency. Third, there is the hybrid system that combines these two types $[3,4]$. When the power grid is normal, it functions as a grid-connection system; when there is some interference with the power grid, it becomes a stand-alone system.

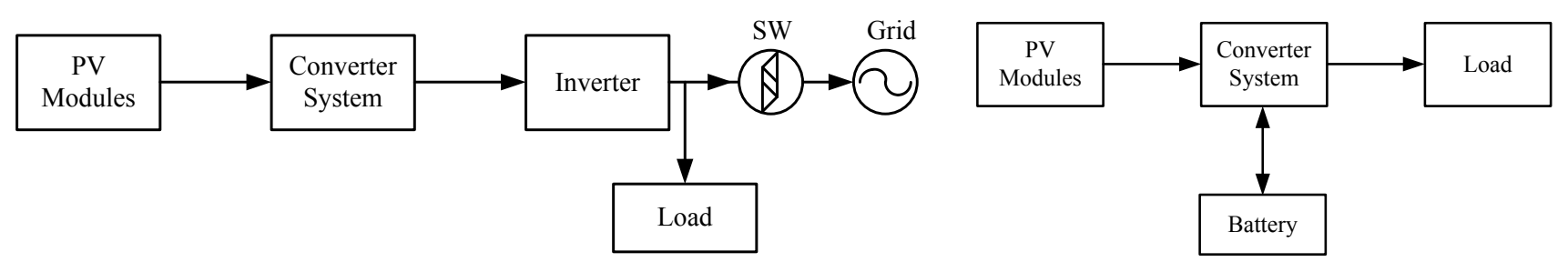

(a)

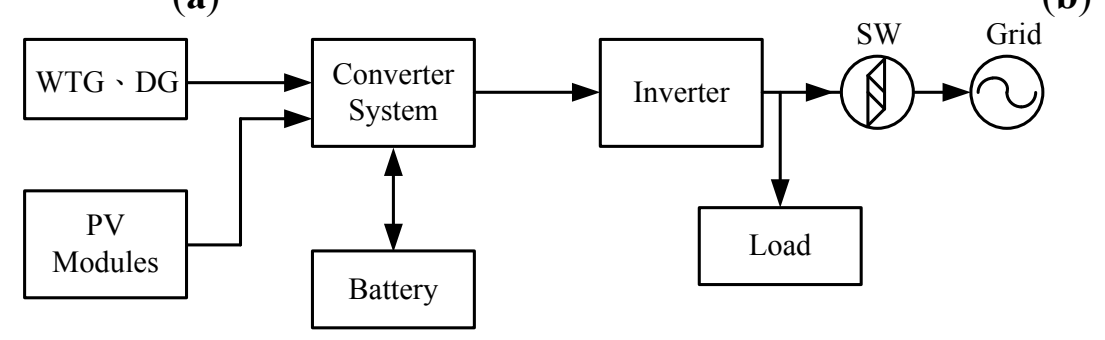

(b)

(c)

Figure 1. Classification of small generation systems with renewable energy: (a) grid-connection system; (b) stand-alone system; and (c) hybrid system. PV: photovoltaic; WTG: wind turbine generator; DG: distributed generation; and SW: switch.

The development of distributed power systems and renewable energy generation makes power converters an important interface [5]. Taking an independent wind power generation system (Figure 2) as an example, wind turbines generate $\mathrm{AC}$ input which is rectified into $\mathrm{DC}$ for a line level control (LLC) converter system. Then it supplies energy to load demand and charge batteries. Although LLC converters have high conversion efficiency under heavy load condition, the large switching loss of LLC converters still results in poor standby power loss; even more, it might consume stored power from batteries in a distributed system [6,7].

The aforementioned conversion systems are adapted for renewable energy power converters, and the limitations of those prior studies are as follows: (1) renewable energy is obtained from natural environment sources, but surely they do not provide a stable energy supply, whereas these prior methods are designed based on situations in which renewable energy can stably carry out its tasks; and (2) LLC converters have issues of standby energy loss, which must be minimized to avoid unnecessary influence on battery energy. 


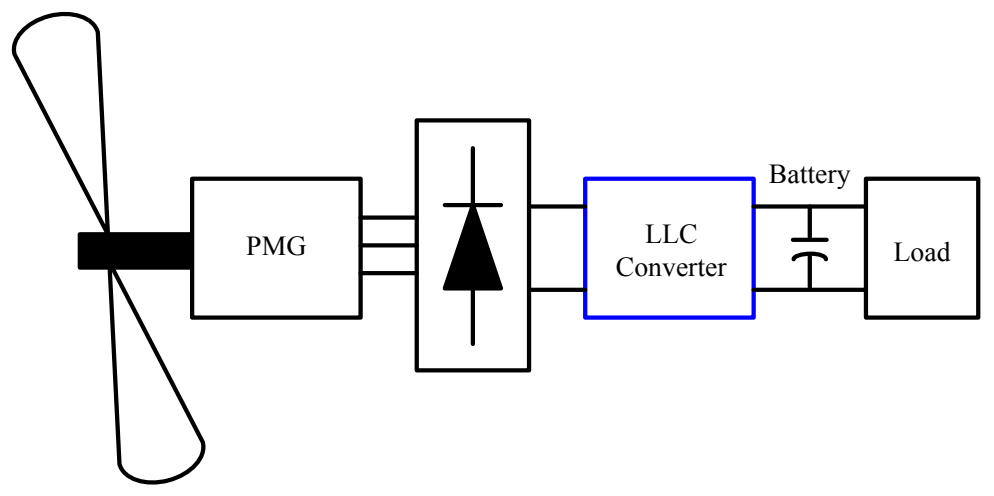

Figure 2. Stand-alone distributed wind power generation system. PMG: permanent magnet generator; and LLC: line level control.

Among several converter types, the LLC converter is the most popular one because it features a wide input range, high conversion efficiency, and high power density, it has been widely applied as a DC/DC power converter [8-10]. For common applications, LLC converters feature high full-load efficiency but provide poor system efficiency during standby because of their large switching losses. They are also compatible with daily-increasing stringent energy regulations and provide fabulous standby efficiency [11-14].

The novel idea of controlling an LLC converter proposed in this paper can reduce the switching losses during standby and allow a wider input range. Under situations with an unstable input source, it can maintain a relatively long period of normal output. The following sections discuss the features and operation principles of this proposed control scheme.

\section{Conventional Schemes}

The circuit of a typical LLC resonant converter is shown in Figure 3. Its control circuit contains a voltage detector, voltage control oscillator (VCO), and dead-time generator. During this control flow, the partial voltage on the output side receives a voltage feedback signal from the voltage detector. It is then transmitted to the VCO to generate a switching frequency corresponding to the voltage feedback signal, and the dead-time generator generates the dead-time interval to send the switching frequency signal to the power switches. When the output partial voltage is greater than the reference voltage, the voltage detector outputs a relatively high output signal to VCO to push it to generate a correspondingly higher switching frequency; on the other hand, when the divided voltage is smaller than the reference voltage, the voltage detector delivers a relatively low output signal to VCO generating a lower switching frequency. The influence of the switching frequency during standby is highly significant, and therefore how to deal with it in an appropriate control scheme becomes an indispensable need.

To facilitate the analysis, we can transform an LLC resonant converter into a primary-side equivalent model. As shown in Figure 4, from this equivalent model, the transfer function is derived as shown in Equation (1):

$$
G(\omega)=\left|\frac{1}{\frac{1}{k}\left(\frac{\omega_{\mathrm{r} 1}^{2}}{\omega_{\mathrm{r} 2}^{2}}-\frac{\omega_{\mathrm{r} 1}^{2}}{\omega_{\mathrm{s}}^{2}}\right)+j Q_{\mathrm{r}}\left(\frac{\omega_{\mathrm{s}}}{\omega_{\mathrm{r} 1}}-\frac{\omega_{\mathrm{r} 1}}{\omega_{\mathrm{s}}}\right)}\right|
$$


where $Q_{\mathrm{r}}=\frac{\sqrt{\frac{L_{\mathrm{r}}}{C_{\mathrm{r}}}}}{R_{\mathrm{o}}}$ is the $Q$-factor, $k=\frac{L_{\mathrm{m}}}{L_{\mathrm{r}}}$ is the ratio between magnetizing inductance and leakage inductance, $\omega_{\mathrm{r} 1}=\frac{1}{\sqrt{L_{\mathrm{r}} C_{\mathrm{r}}}}$ is the first resonance frequency, and $\omega_{\mathrm{r} 2}=\frac{1}{\sqrt{\left(L_{\mathrm{r}}+L_{\mathrm{m}}\right) C_{\mathrm{r}}}}$ is the second resonance frequency.

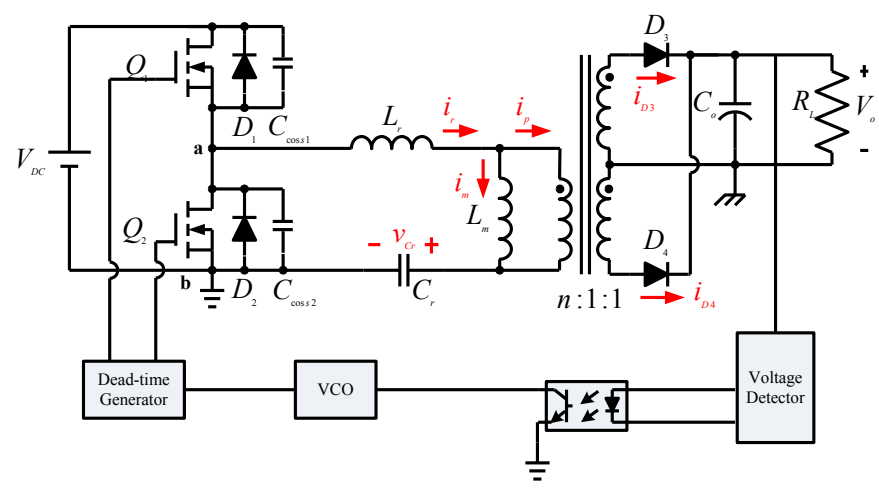

Figure 3. Schematic of LLC resonant converter with basic functional blocks. VCO: voltage control oscillator.

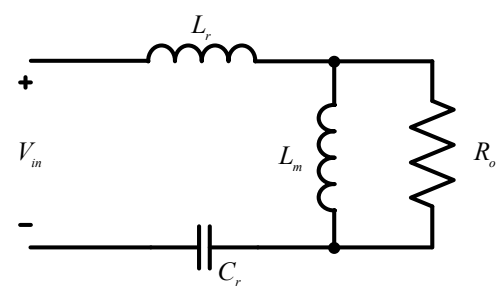

Figure 4. Primary-side equivalent model of LLC resonant converter.

Equation (1) is plotted as the characteristic curve of voltage gain relative to frequency, as shown in Figure 5. By means of two resonant frequencies of $\omega_{\mathrm{r} 1}$ and $\omega_{\mathrm{r} 2}$, it can designate three regions: (1) Region 1 is the zero voltage switching (ZVS) region in the right half-plane of $\omega_{\mathrm{rr}}$; (2) Region 2 is the ZVS region between $\omega_{\mathrm{r} 1}$ and $\omega_{\mathrm{r} 2}$; and (3) Region 3 is the zero current switching (ZCS) region in the left half-plane of $\omega_{\mathrm{r} 2}$.

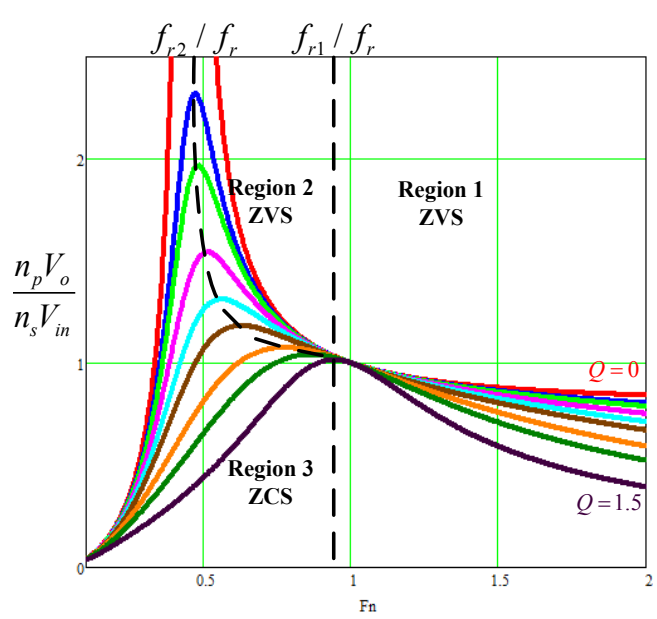

Figure 5. Characteristic curves of voltage gain of LLC resonant converter with respect to frequency. 
Metal-oxide-semiconductor field-effect transistor (MOSFET) operation performs relatively well in ZVS mode, and therefore LLC resonant converters mostly work in Regions 1 and 2.

\subsection{Operation of the Line Level Control Resonant Converter in Region 1 (Zero Voltage Switching)}

The waveform when switching frequency is located at Region 1, as shown in Figure 6. In this region, the magnetizing inductance $L_{\mathrm{m}}$ is clamped by the output voltage, and the entire duty cycle $L_{\mathrm{m}}$ is not included in the resonance. Therefore, the operation mode at this condition acts similar to SRC with ZVS characteristics.

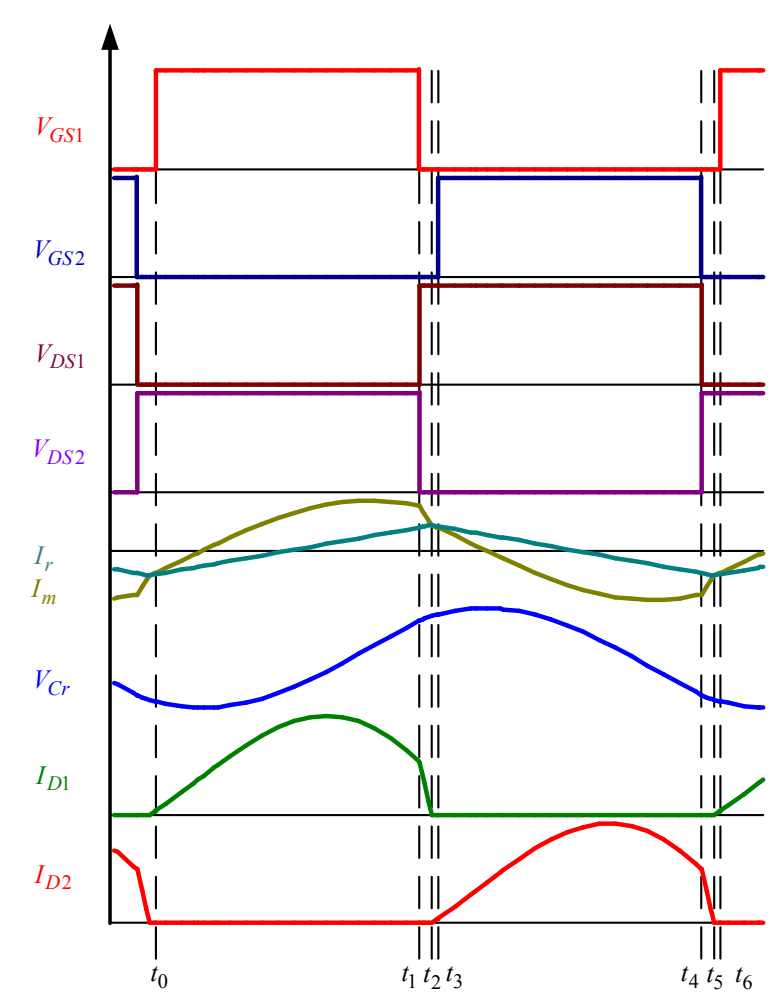

Figure 6. Schematic diagram of LLC resonant converter operated in Region 1 (zero voltage switching, ZVS).

\subsection{Operation of the Line Level Control Resonant Converter in Region 2 (Zero Voltage Switching)}

When the switching frequency is located in Region 2, the waveform is shown in Figure 7. The resonance in this region is divided into two stages. In the first stage $t_{0}-t_{3}$, the magnetizing inductance $L_{\mathrm{m}}$ is clamped by the output voltage, with $L_{\mathrm{m}}$ non-inclusive in resonance, and the resonant inductance $L_{\mathrm{r}}$ resonates with capacitor $C_{\mathrm{r}}$; in the second stage $t_{3}-t_{4}$, when the resonant current $i_{\mathrm{r}}$ is equal to the side magnetizing inductance current $i_{L \mathrm{~m}}$, there is no current flowing into transformer, and the secondary side of the converter is tantamount to an open circuit when the magnetizing inductance $L \mathrm{~m}$ will resonate with the resonant inductance $L_{\mathrm{r}}$ and the resonant capacitor $C_{\mathrm{r}}$. Because Region 2 has two resonance frequencies, it is a multi-resonant converter.

The control mode of typical LLC converters is that the output voltage provides feedback to VCO to adjust output power by changing the switching frequency. However, shortcoming of LLC converters is the inferior standby efficiency and relatively high output voltage during no-load. Thus, it causes 
no-load switching frequency increases to two to four times than full-load switching frequency, and results in double switching loss.

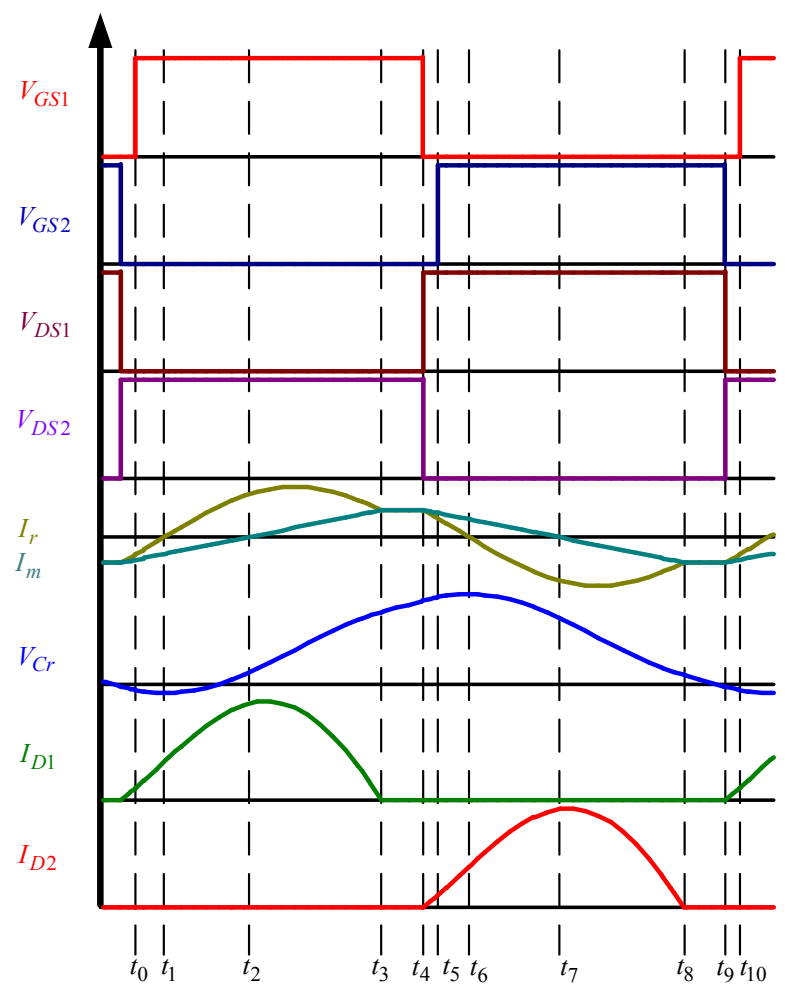

Figure 7. Schematic diagram of LLC resonant converter operated in the mode of Region 2 (ZVS).

To solve the issue of high switching frequency and low efficiency of LLC resonant converters operated at standby, a large number of studies have focused on how to improve standby efficiency, such as burst mode, output saturation inductance, and dummy load regulation. The mostly common approach is burst mode control.

When entering burst mode, it blocks the original high-frequency switching signal by the control circuit, causing episodic high-frequency switching frequency and reducing unnecessary switching loss. Figure 8 shows the burst mode schematics.
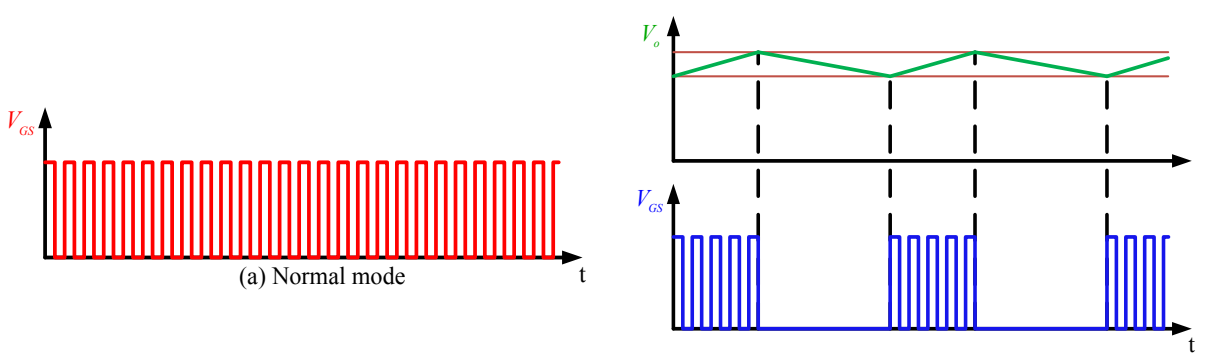

(b) Burst mode

Figure 8. Diagram of burst mode: (a) normal mode; and (b) burst mode.

The typical control block diagram is shown in Figure 9, and the output signal of VCO sent to logic circuits determines time interval for the switching signal needing masked. However, the drawback is that ripples grow relatively large, and prone to generating audio noise. 


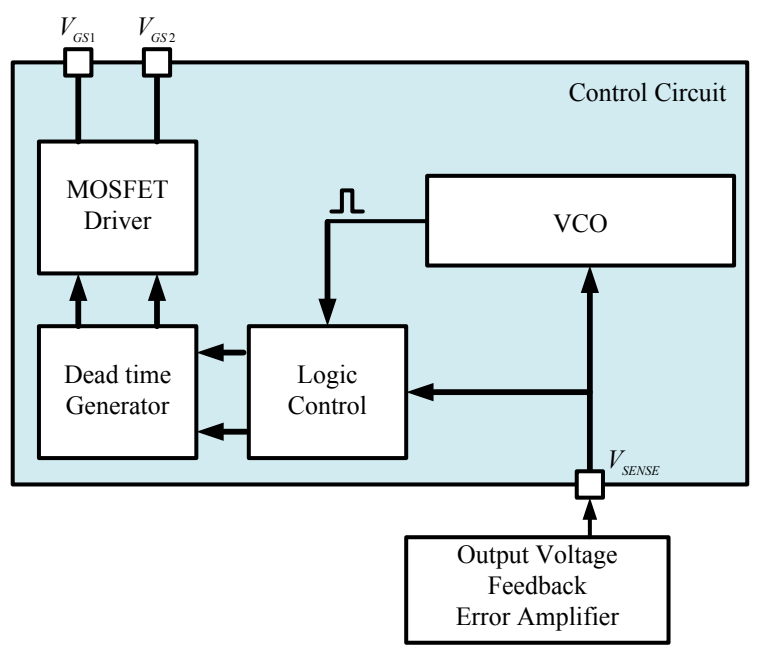

Figure 9. Block diagram of typical control circuit with burst mode. MOSFET: metal-oxide-semiconductor field-effect transistor.

In the next section, SIMPLIS simulation supports establishing behaviors of a typical LLC circuit. For the purpose of making simulation results match the real circuit, the simulated system needs to take parasitic devices into consideration, which probably affects the resonant frequency and voltage gain, and parasitic capacitance especially affects the operating frequency. To simplify the analysis and make simulation converged easily, the revised paper moves all secondary parasitic capacitance to primary side and merges overall parasitic capacitance as equivalent parallel capacitance $C_{\mathrm{P}}$ [11].

Simulation condition 1: Figure 10 shows simulated waveforms of a typical LLC circuit under $480 \mathrm{~W} / 48 \mathrm{~V}$, which adopts VCO to adjust the power. Therefore, the switching frequency varies with load.

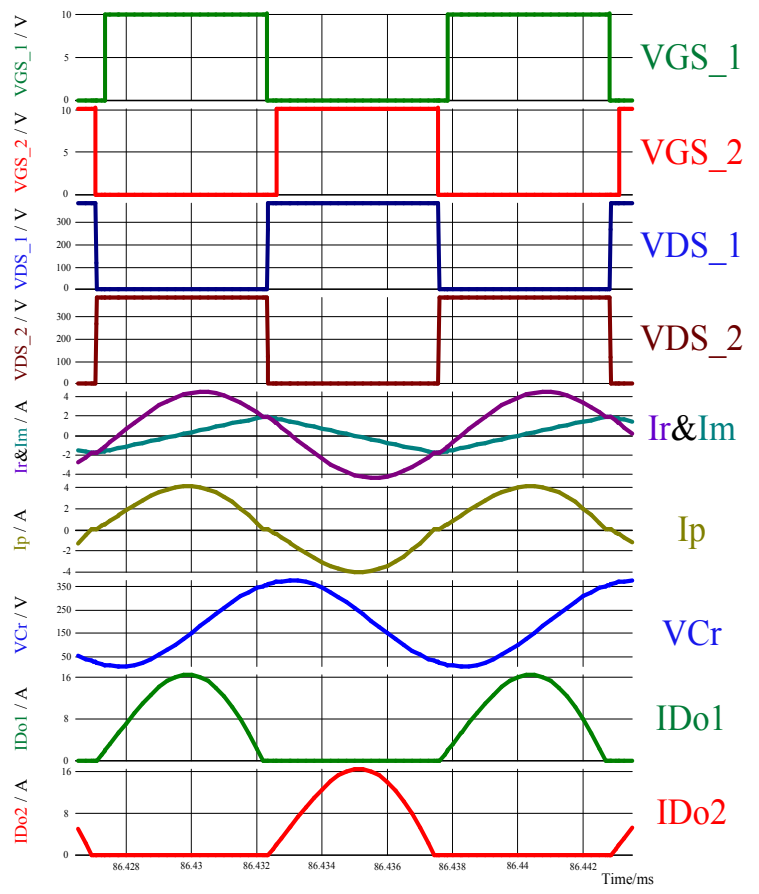

(a)

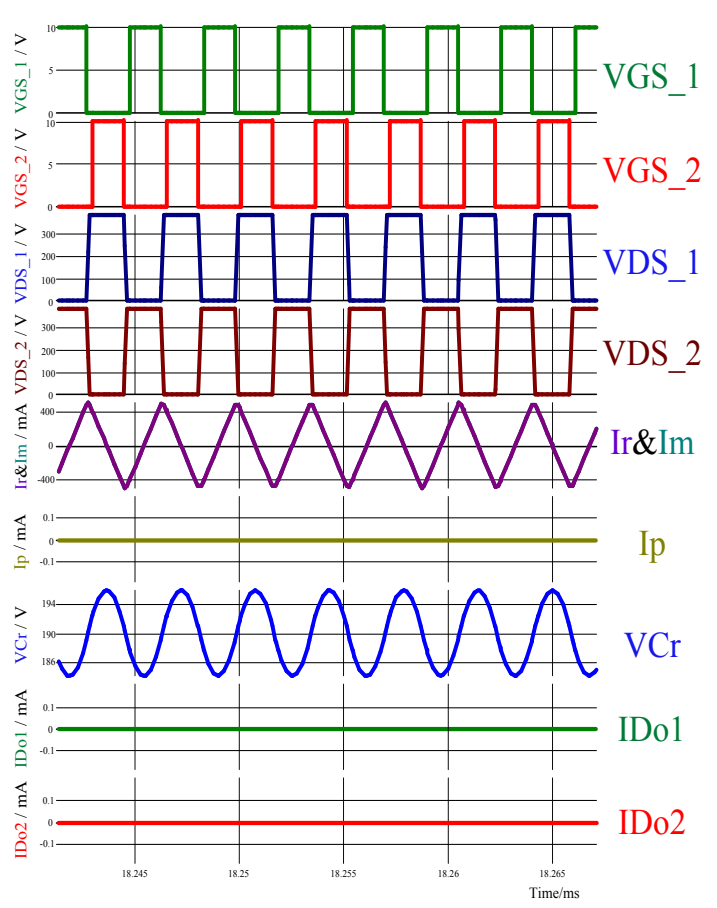

(b)

Figure 10. Simulation waveforms for typical LLC circuit at $480 \mathrm{~W} / 48 \mathrm{~V}$ : (a) 100\% load; and (b) $0 \%$ load. 
Simulation condition 2: to observe differences between middle and high power, typical LLC circuit for $1200 \mathrm{~W} / 48 \mathrm{~V}$ plays the role of comparable prototype. Figure 11 shows simulations waveform of $1200 \mathrm{~W} / 48 \mathrm{~V}$.

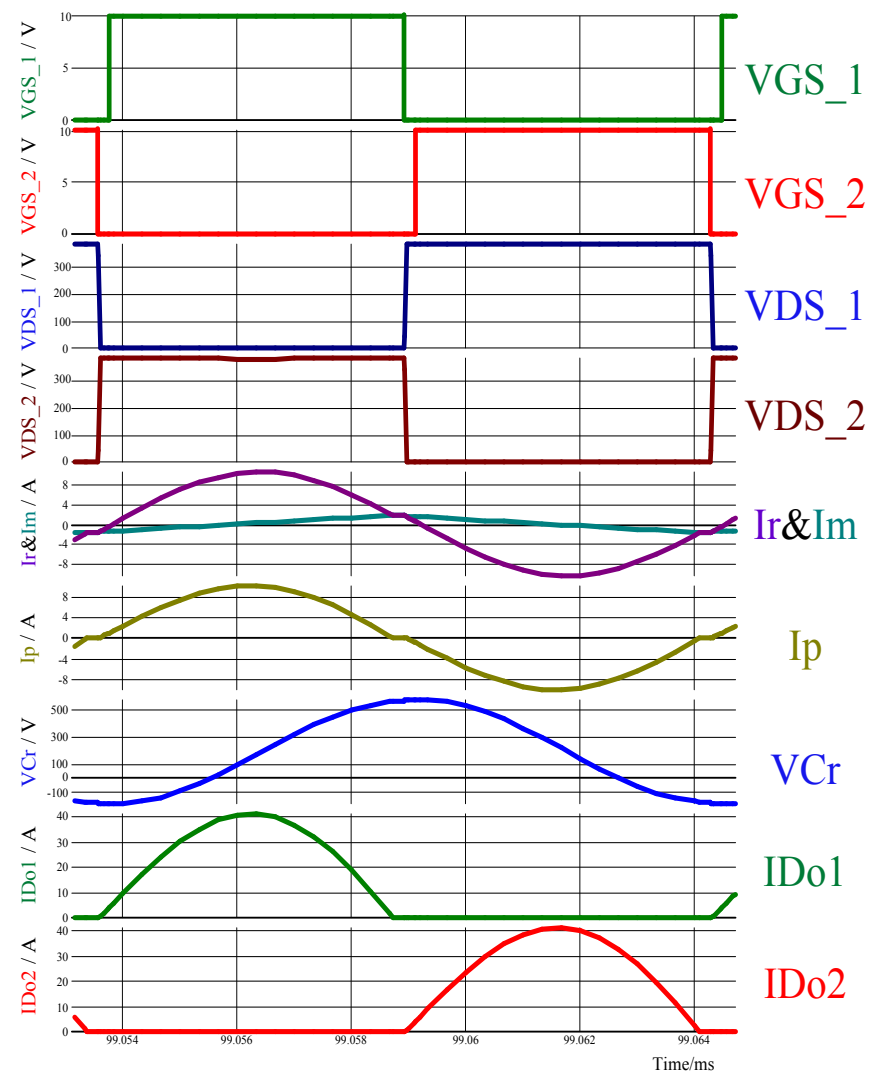

(a)

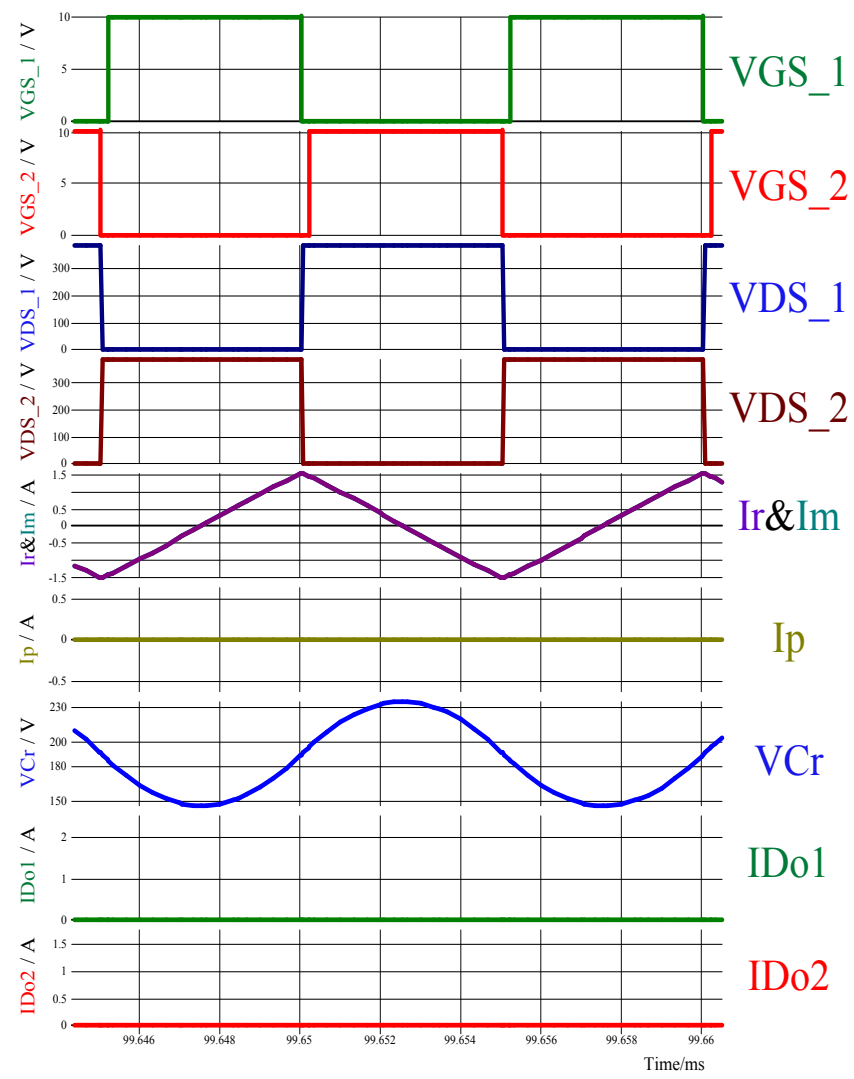

(b)

Figure 11. Simulation waveforms for a typical LLC circuit at $1200 \mathrm{~W} / 48 \mathrm{~V}$ : (a) 100\% load; and (b) $0 \%$ load.

This section describes the operation principles of typical LLC circuits and provides some analysis for different loads. It shows that switching frequency at standby is approximately twice than full-load switching frequency.

\section{Novel Line Level Control Circuit}

To solve problems of high switching loss upon standby, a novel LLC control circuit is proposed as shown in Figure 12.

When the proposed circuit operates in full-load, the power switch $Q_{3}$ of the auxiliary control circuit can be synchronously conducted with the frequency of the primary oscillator and stops as it reaches the condition of the feedback signal of output voltage, which causes the auxiliary switch $Q_{3}$ operating with the synchronized pulse-width-modulation (PWM) mode. If the load declines, the duty cycle of the auxiliary switch also decreases; when operated in no-load situations, the duty cycle of the auxiliary switch $Q_{3}$ is equal to 0 , and makes $Q_{3}$ closed. Figure 13 plots main waveforms when the new LLC control circuit operates in full-load situations, which can be divided into four working states. 


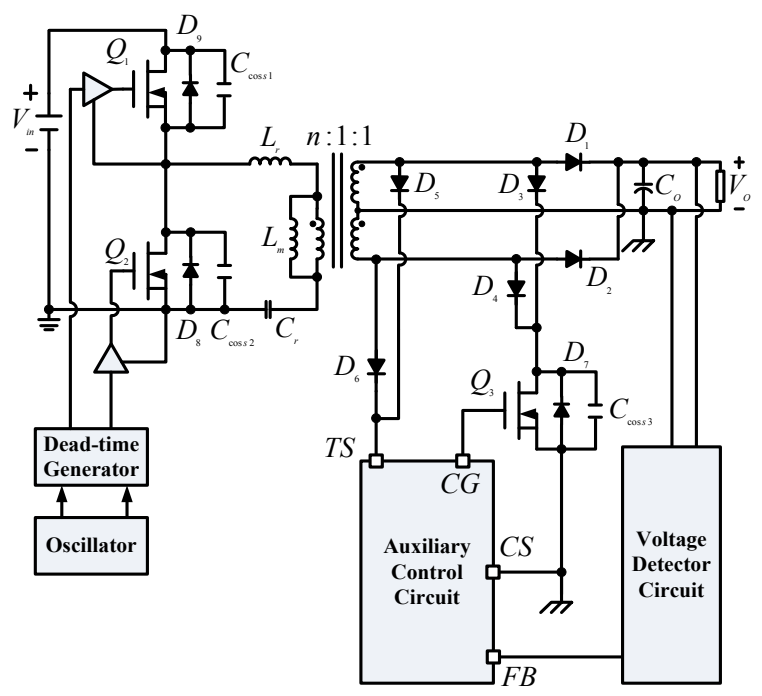

Figure 12. Structural diagram of a novel LLC control circuit.

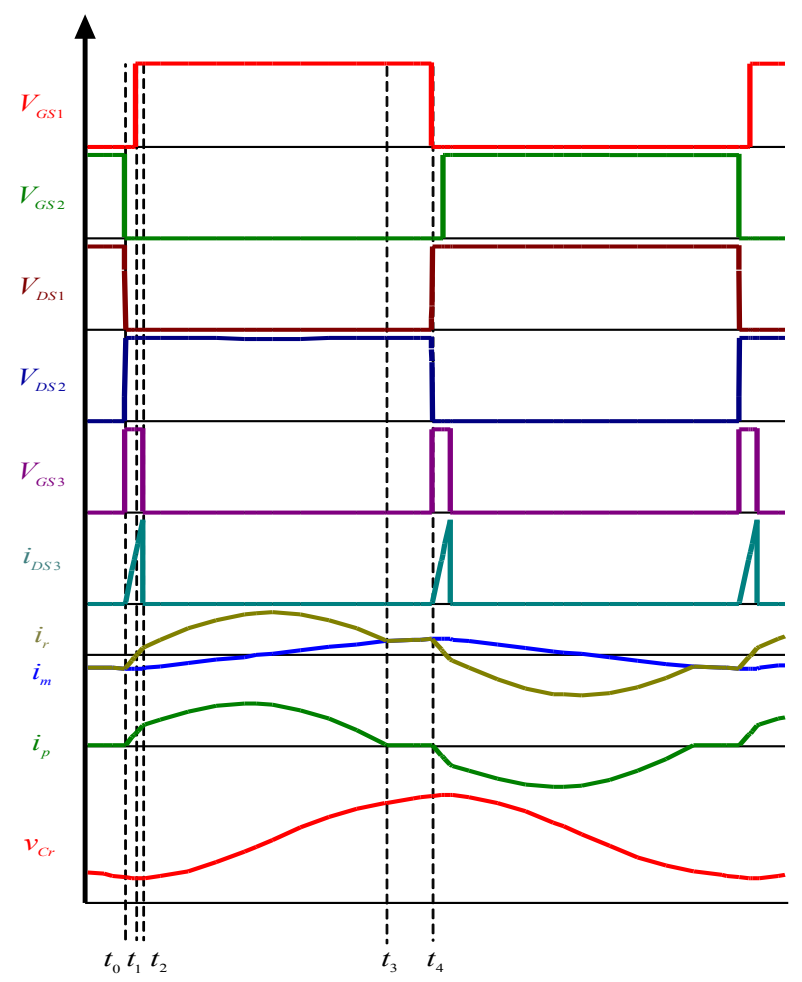

Figure 13. Main waveforms of novel LLC control circuit.

\subsection{Working State $1\left(t_{0} \leq t \leq t_{1}\right)$}

In Working State 1, shown in Figure 14, the upper-bridge switch parasitic capacitor $C_{\text {coss } 1}$ has been discharged to zero, whereas the voltage of the lower-bridge parasitic capacitor $C_{\text {coss } 2,} V_{\mathrm{DS} 2}$, has been charged from 0 to $V_{\text {in. }}$. The upper-bridge parasitic diode $D_{9}$ is conducted, reaching the condition for the ZVS of the upper-bridge switch $Q_{1}$. The auxiliary switch $Q_{3}$ is synchronously conducted along with the state transfer of $V_{\mathrm{DS} 2}$. At this time, the circuit is operated in the current enhancement mode, and the secondary converter is shorted out by auxiliary switch $Q_{3}$. No energy is delivered to the load end, and the energy for the load is provided by the output capacitor $C_{0}$. Because the secondary converter is 
shorted out, the voltage over the two ends of the magnetizing inductance $L_{\mathrm{m}}$ is clamped at zero, and the magnetizing current $i_{\mathrm{m}}$ is maintained at $i_{\mathrm{m}}\left(t_{0}\right)$ without changing. The voltage across the resonant inductance $L_{\mathrm{r}}$ also increases due to the secondary short circuit when only the resonant inductance $L_{\mathrm{r}}$ and resonant capacitor $C_{\text {r }}$ participate in resonance. However, due to the secondary short circuit, the resonant circuit $i_{\mathrm{r}}(t)$ is forced to undergo a relatively rapid linear increase. At $t=t_{1}$, the upper-bridge switch $Q_{1}$ is conducted to complete the zero-voltage switching. At this instant, the resonant current $i_{\mathrm{r}}(t)$ increases to zero, and this mode ends.

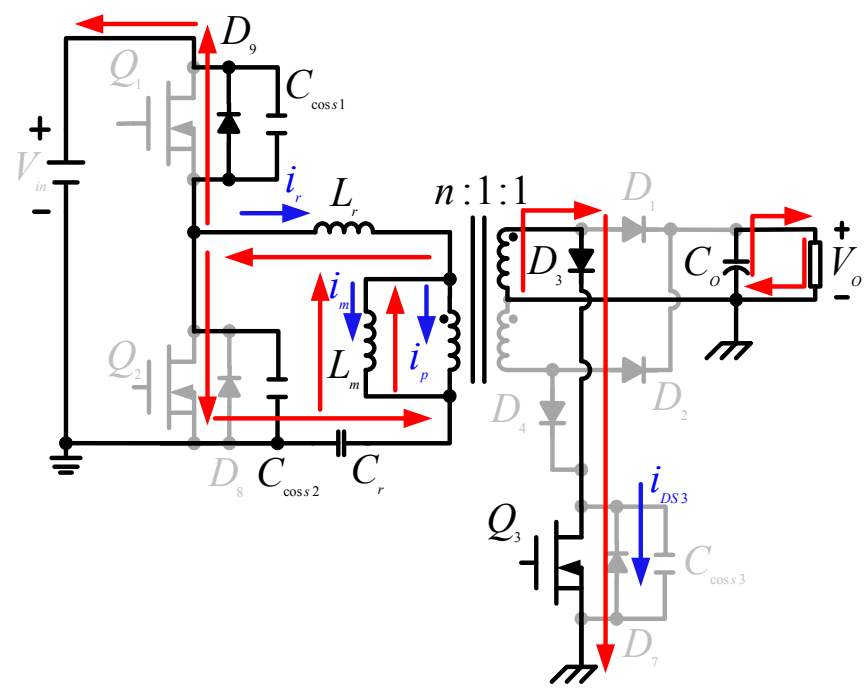

Figure 14. Working State 1 of novel LLC control circuit.

\subsection{Working State $2\left(t_{1} \leq t \leq t_{2}\right)$}

In this working state, the two ends of magnetizing inductance $L_{\mathrm{m}}$ are still clamped at zero by the secondary short circuit, and the magnetizing current $i_{\mathrm{m}}$ is maintained at $i_{\mathrm{m}}\left(t_{0}\right)$ without changing; at this time, only the resonant inductance $L_{\mathrm{r}}$ and resonant capacitance $C_{r}$ participate in the resonance, whereas the resonant current $i_{\mathrm{r}}$ continues to undergo a rapid linear increase. The state of the circuit is shown in Figure 15 . At $t=t_{2}$, the auxiliary circuit stops the auxiliary switch $Q_{3}$, and this mode ends.

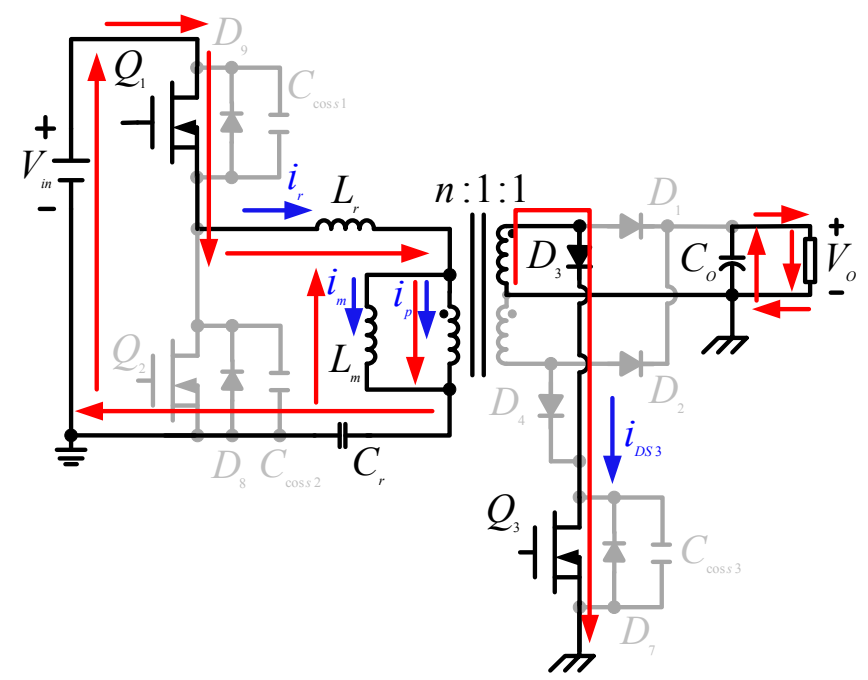

Figure 15. Working State 2 of novel LLC control circuit. 


\subsection{Working State $3\left(t_{2} \leq t \leq t_{3}\right)$}

In Working State 3, shown in Figure 16, the two ends of the magnetizing inductance $L_{\mathrm{m}}$ are clamped at $n V_{\mathrm{o}}$ by the output voltage, and therefore, the magnetizing current $i_{m}$ continues to increase linearly; only the resonant inductance $L_{\mathrm{r}}$ and the resonant capacitor $C_{r}$ still participate in the resonance, but the resonant current $i_{\text {r }}$ restores to increase as a sinusoidal waveform. When $t=t_{3}$, the resonant current $i_{\mathrm{r}}$ is equal to the magnetizing current $i_{\mathrm{m}}$. The current through the output rectifier diode $D_{1}, i_{D 1}$, resonates to zero and stops, completing ZCS, and this mode is over.

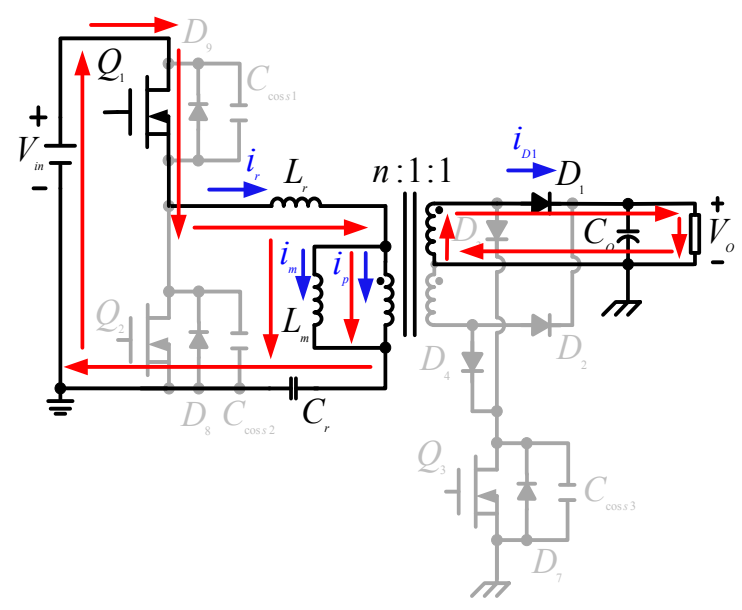

Figure 16. Working State 3 of novel LLC control circuit.

\subsection{Working State $4\left(t_{3} \leq t \leq t_{4}\right)$}

In Working State 4 in Figure 17, because the output rectifier diode is turned off, the power on the input end cannot be delivered to the secondary load, and the converter is in the decoupled state. At this time, the resonant inductance $L_{r}$ and resonant capacitance $C_{r}$ resonate with the magnetizing inductance $L_{\mathrm{m}}$; because the magnetizing inductance $L_{\mathrm{m}}$ is much larger than the resonant inductance $L_{\mathrm{r}}$, the resonance frequency decreases, and the resonant current waveforms $i_{\mathrm{r}}$ becomes relatively flat. Because the resonant current through the resonant inductance $L_{\mathrm{r}}, i_{\mathrm{r}}$, is continuous, the resonant current $i_{\mathrm{r}}$ continues to charge the resonant capacitor $C_{\mathrm{r}}$. At $t=t_{4}$, upper-bridge switch $Q_{1}$ turns off, and this state ends.

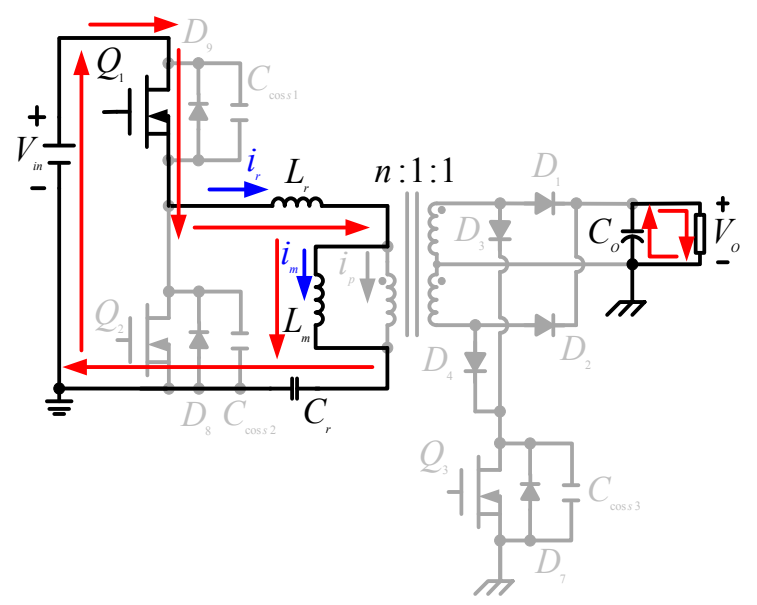

Figure 17. Working State 4 of novel LLC control circuit. 
Now that operation principles is clarified, first presume that input voltage $V_{\mathrm{o}}$ and output voltage $V_{\mathrm{o}}$ are both constant in one switching period. Furthermore, to simplify analysis, assume that the magnetizing inductance $L_{\mathrm{m}}$ is very large, and therefore magnetizing current $i_{\mathrm{m}}$ is zero. It can be derived that the equation for voltage gain is given by Equation (2):

$$
\frac{n V_{\mathrm{o}}}{\frac{V_{\mathrm{in}}}{2}}=\frac{\frac{T_{\mathrm{s}}}{C_{\mathrm{r}} R_{\mathrm{ac}}}+\sqrt{\left(\frac{T_{\mathrm{s}}}{C_{\mathrm{r}} R_{\mathrm{ac}}}\right)^{2}+4\left[1-\cos ^{2}\left(\omega_{\mathrm{r} 1} \frac{D T_{\mathrm{s}}}{2}\right)\right] \frac{T_{\mathrm{s}}}{C_{\mathrm{r}} R_{\mathrm{ac}}}}}{2 n\left[1+\cos \left(\omega_{\mathrm{r} 1} \frac{D T_{\mathrm{s}}}{2}\right)\right] \frac{T_{\mathrm{s}}}{C_{\mathrm{r}} R_{\mathrm{ac}}}}
$$

Voltage gain curves are plotted based on above equations, as shown in Figure 18. It indicates the auxiliary switch $Q_{3}$ plays a role in increasing resonant current $i_{\text {r. }}$ Along with the duty cycle $D$ of auxiliary switch $Q_{3}$ increasing, higher voltage gains can be obtained.

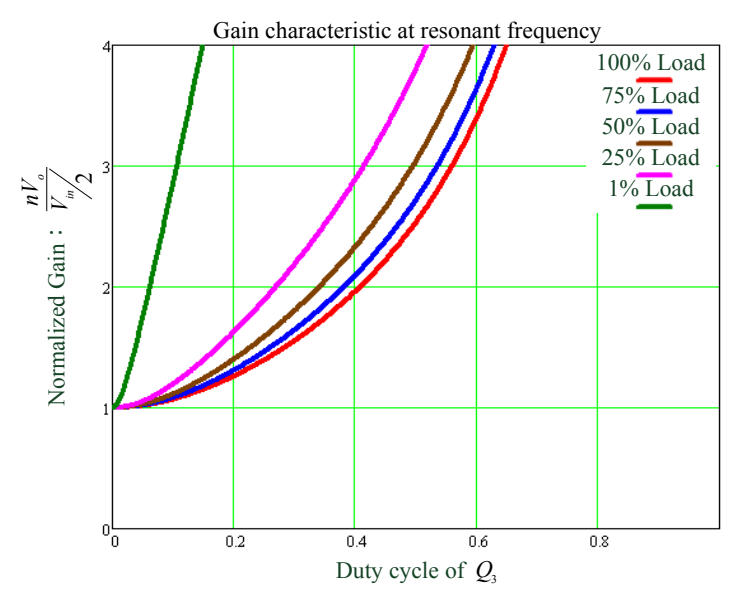

Figure 18. Characteristic plots of system gain that changes with load.

From the perspective of the resonant tank, Figure 19 shows the characteristic relationship curve between resonant tank parameters and system gain with fixed magnetizing inductance. Moreover, it also indicates the lower resonant inductance $L_{\mathrm{r}}$ induces the higher system gain during the same operation period $D$. It means that the lower design resonant inductance $L_{\mathrm{r}}$ adopts, the higher current gain the system gets.

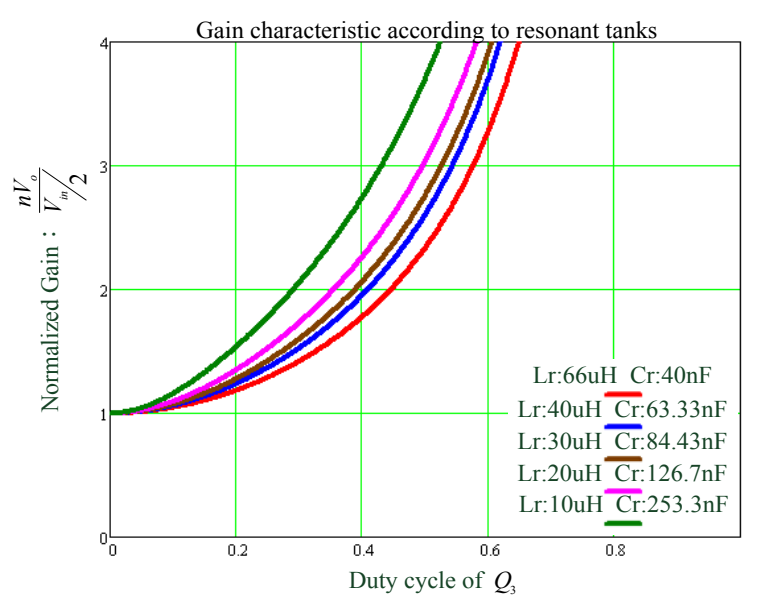

Figure 19. Characteristic plots of system gain changing with resonant tank. 
By means of the auxiliary control circuit shown in Figure 20, the above functions are achieved, and the auxiliary control circuit also has the function of sequential detection and voltage detection.

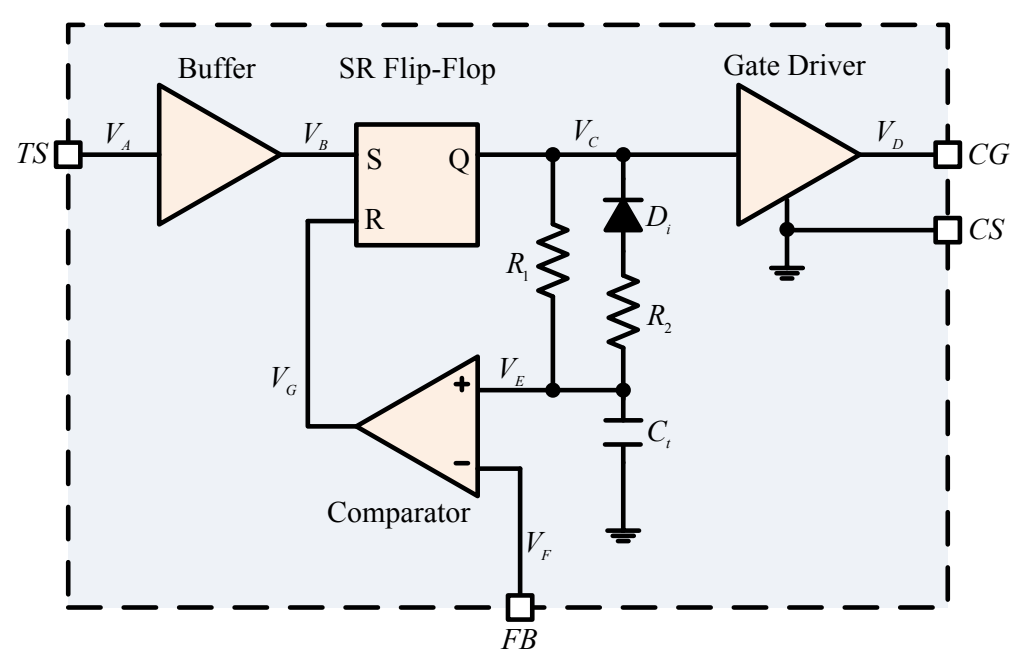

Figure 20. Block diagram of auxiliary control circuit.

Figure 21 shows waveforms of the auxiliary control circuit.

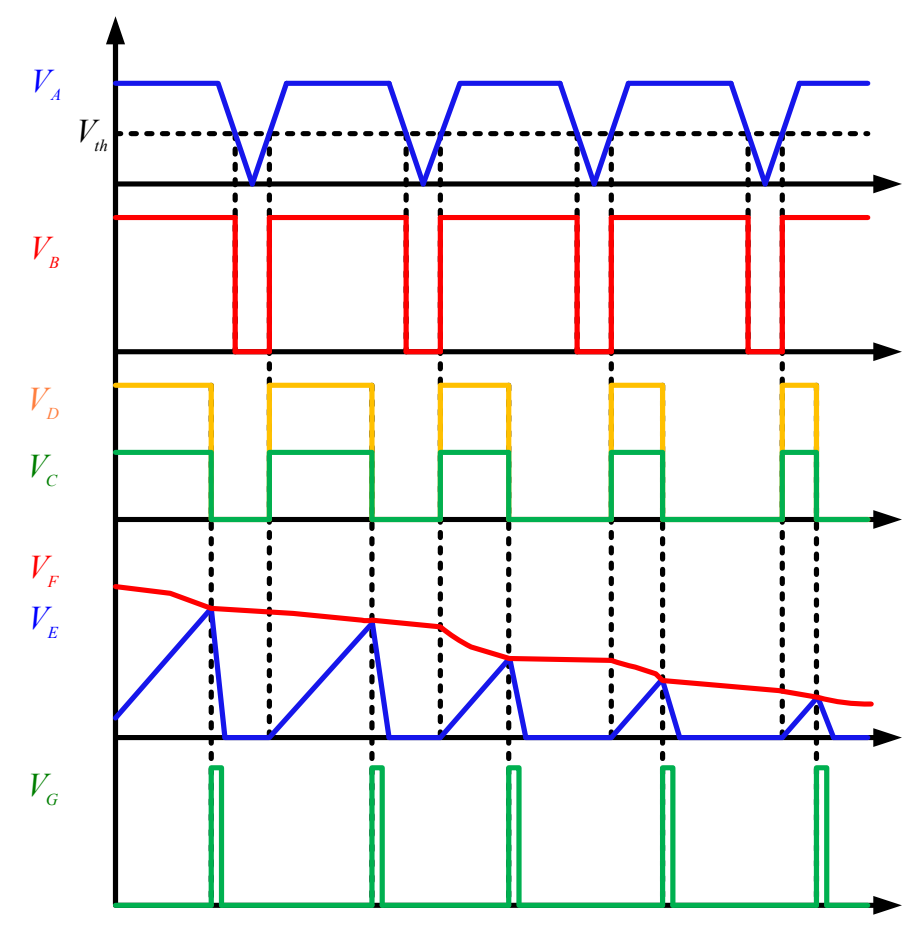

Figure 21. Principle waveforms of auxiliary control circuit.

The next section will report simulation results and analysis for novel LLC control circuits.

\section{Simulation Results and Analysis}

Based on the theoretical analysis above, feasibility of the method proposed in this paper can be verified with the help of SIMPLIS simulation, and the performances acquired by simulation obviously demonstrates it getting overwhelming superior positions in comparison of conventional type circuit: 
(1) The simulated circuit and function block diagram are built and behaves following proposed operation principles truly, as shown in Figure 22.

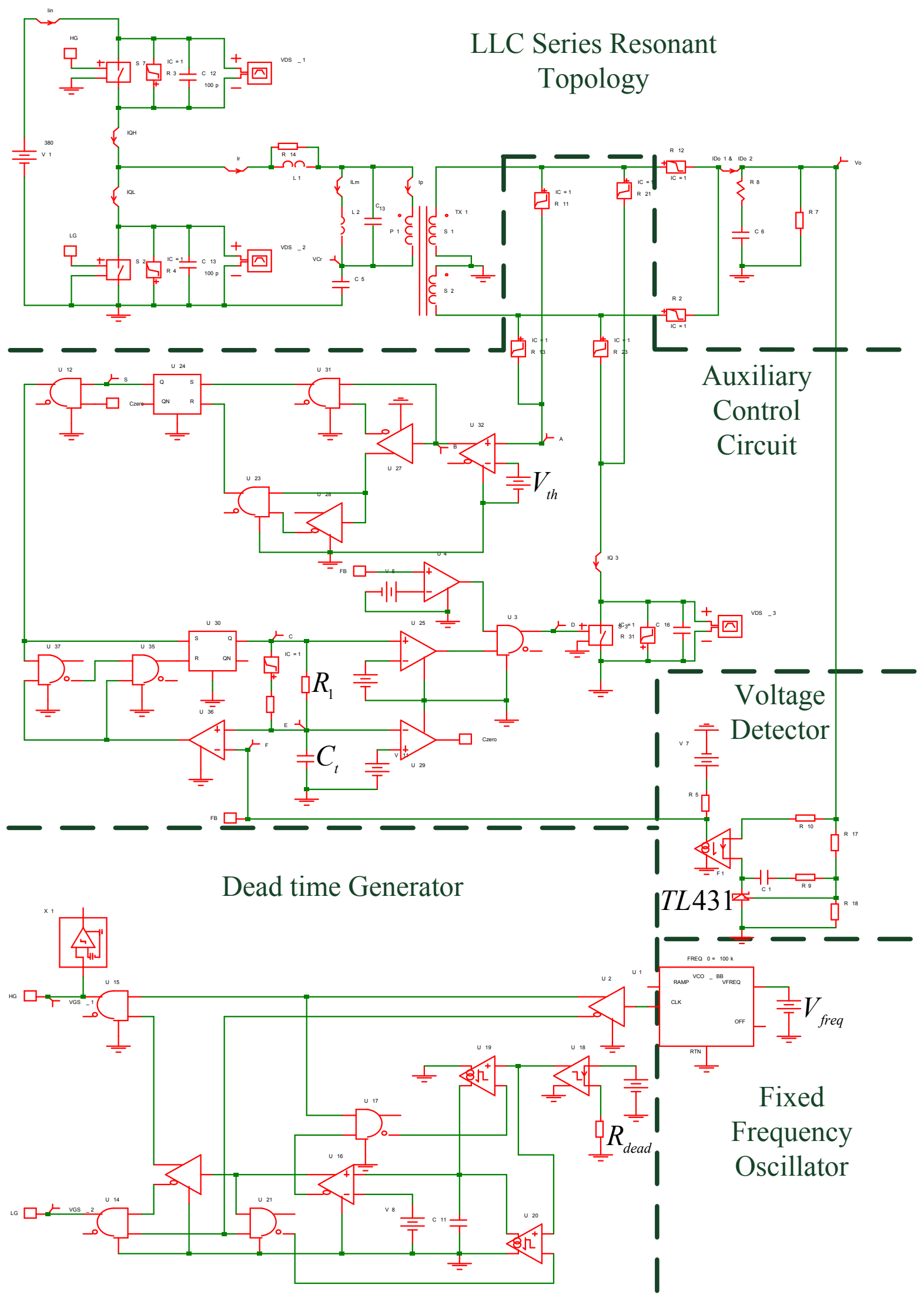

Figure 22. Novel LLC simulation circuit. 
Simulation condition 3 (novel LLC control circuit): $P_{\mathrm{omax}}=480 \mathrm{~W}, V_{\mathrm{o}}=48 \mathrm{~V}, L_{\mathrm{m}}=264 \mu \mathrm{H}, L_{\mathrm{r}}=30 \mu \mathrm{H}$, $C_{\mathrm{r}}=100 \mathrm{nF}$, and $C_{\mathrm{P}}=12.28 \mathrm{nF}$.

Simulation condition 4 (novel LLC control circuit): $P_{\text {omax }}=1200 \mathrm{~W}, V_{\mathrm{o}}=48 \mathrm{~V}, L_{\mathrm{m}}=264 \mu \mathrm{H}$, $L_{\mathrm{r}}=20 \mu \mathrm{H}, C_{\mathrm{r}}=130 \mathrm{nF}$, and $C_{\mathrm{P}}=30.72 \mathrm{nF}$.

Table 1 lists simulation result comparisons between the novel LLC control circuits and typical LLC circuits. This table shows that switching frequency of typical LLC resonant converters at standby tends to reach even twice than that at full-load, whereas the novel LLC control circuit still operates at fixed frequency regardless of whether in standby or full-load conditions. By attributions from power switch of the auxiliary control circuit keeping in cut-off state, switching loss degrades accompanied with a relatively large peak input current, $I_{\text {in_peak. }}$

Table 1. Comparison between the simulation results for typical LLC circuit and new LLC circuit.

\begin{tabular}{|c|c|c|c|c|}
\hline 480 W/48 V@100\% load & $f_{\mathrm{Sw}}$ & \multicolumn{2}{|c|}{$I_{\text {in_peak }}$} & $f_{\mathrm{Q} 3}$ \\
\hline Conventional LLC & $98.89 \mathrm{kHz}$ & \multicolumn{2}{|c|}{$4.521 \mathrm{~A}$} & $\mathrm{~N} / \mathrm{A}$ \\
\hline Proposed LLC & $99 \mathrm{kHz}$ & \multicolumn{2}{|c|}{$6.827 \mathrm{~A}$} & $198 \mathrm{kHz}$ \\
\hline 480 W/48 V@0\% load & $f_{\mathrm{sw}}$ & $I_{\text {in_peak }}$ & $I_{\text {in_rms }}$ & $f_{\mathrm{Q} 3}$ \\
\hline Conventional LLC & $285.15 \mathrm{kHz}$ & $0.688 \mathrm{~A}$ & $0.327 \mathrm{~A}$ & $\mathrm{~N} / \mathrm{A}$ \\
\hline Proposed LLC & $95 \mathrm{kHz}$ & $1.018 \mathrm{~A}$ & $0.486 \mathrm{~A}$ & $0 \mathrm{~Hz}$ \\
\hline 1200 W/48 V@100\% load & $f_{\mathrm{SW}}$ & \multicolumn{2}{|c|}{$I_{\text {in_peak }}$} & $f_{\mathrm{Q} 3}$ \\
\hline Conventional LLC & $96.52 \mathrm{kHz}$ & \multicolumn{2}{|c|}{$12.016 \mathrm{~A}$} & $\mathrm{~N} / \mathrm{A}$ \\
\hline Proposed LLC & $96 \mathrm{kHz}$ & \multicolumn{2}{|c|}{$23.791 \mathrm{~A}$} & $186 \mathrm{kHz}$ \\
\hline 1200 W/48 V@0\% load & $f_{\mathrm{SW}}$ & $I_{\text {in_peak }}$ & $I_{\text {in_rms }}$ & $f_{\mathrm{Q} 3}$ \\
\hline Conventional LLC & $258.47 \mathrm{kHz}$ & $1.810 \mathrm{~A}$ & $0.824 \mathrm{~A}$ & N/A \\
\hline Proposed LLC & $96 \mathrm{kHz}$ & $2.360 \mathrm{~A}$ & $1.076 \mathrm{~A}$ & $0 \mathrm{~Hz}$ \\
\hline
\end{tabular}

According to the formulas for the LLC resonant converter operated under no load conditions, the dominant power loss is roughly divided into four parts, such as switching loss and conduction loss on power switches, copper loss and core loss on the transformer. Besides, the material of cores and temperature-related parameters on transformers cannot be rebuilt accurately in a simulated system, which makes it not convincing if core loss is taken into consideration in the simulation. Thus, this paper ignores core loss estimation:

$$
\begin{gathered}
P_{\text {turn-off_loss }}=\frac{1}{2} \times V_{\mathrm{DS}} \times I_{\text {DS_Peak }} \times t_{\mathrm{f}} \times f_{\mathrm{s}} \\
P_{\text {conduction_loss }}=I_{\mathrm{DS} \_ \text {RMS }} \times R_{\text {DS_on }} \\
P_{\text {core }}=C_{\mathrm{m}} \times f^{x} \times B_{\text {peak }}^{y} \times\left(c t_{0}-c t_{1} \times T+c t_{2} \times T^{2}\right) \\
P_{\text {Copper }}=I_{\text {in_rms }}{ }^{2} \times R_{\text {pri }}+I_{\text {sec_rms }}{ }^{2} \times R_{\text {sec }}
\end{gathered}
$$

Proved by Figures 23 and 24 and Tables 1 and 2, LLC systems with the novel control circuit perform better efficiency at standby. 


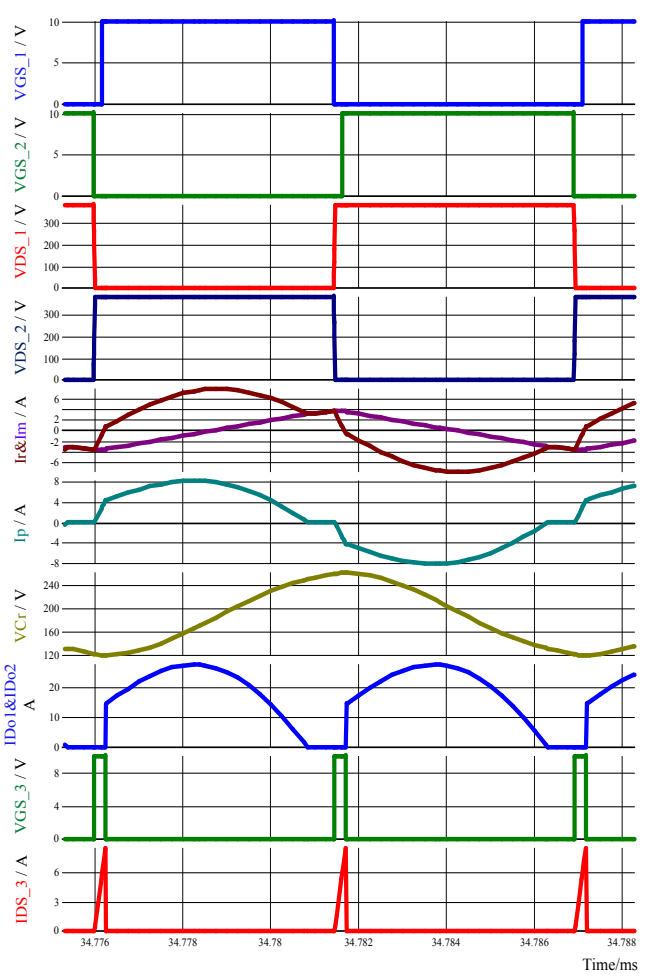

(a)

VGS_1
VGS_2
VDS_1
VDS_2
Ir\&Im
Ip
VCr
Do1\&IDo2
VGS_3
IDS_3

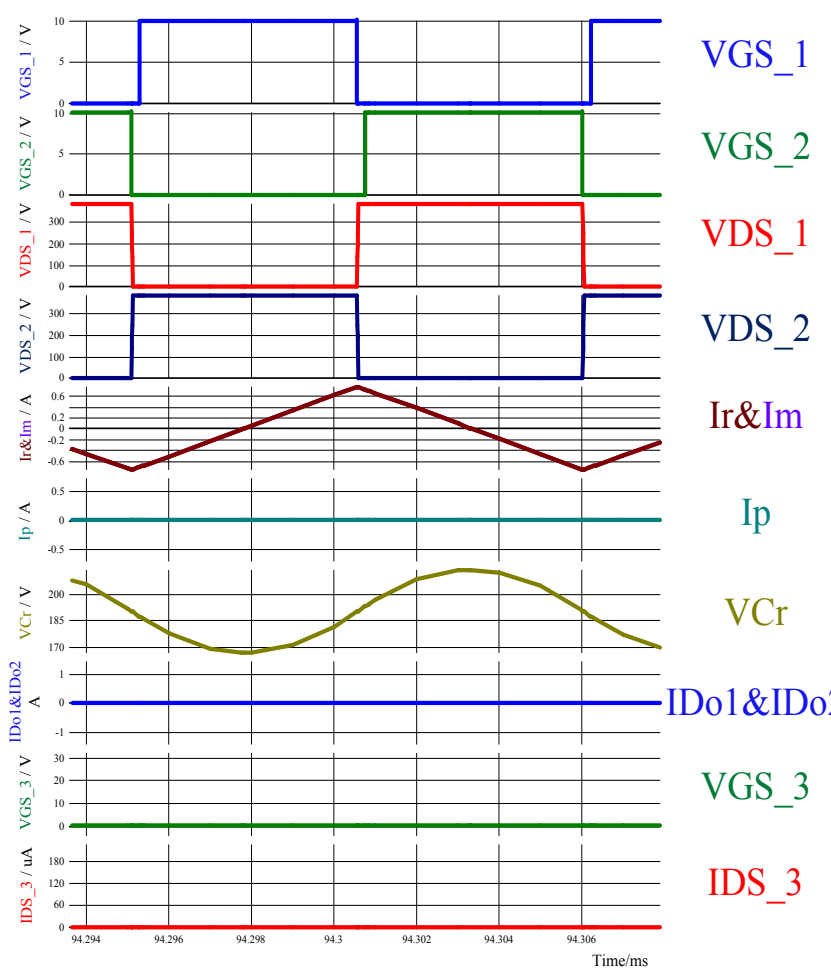

(b)

Figure 23. Simulation waveforms for novel LLC control circuit at $480 \mathrm{~W} / 48 \mathrm{~V}$ : (a) 100\% load; and (b) $0 \%$ load.

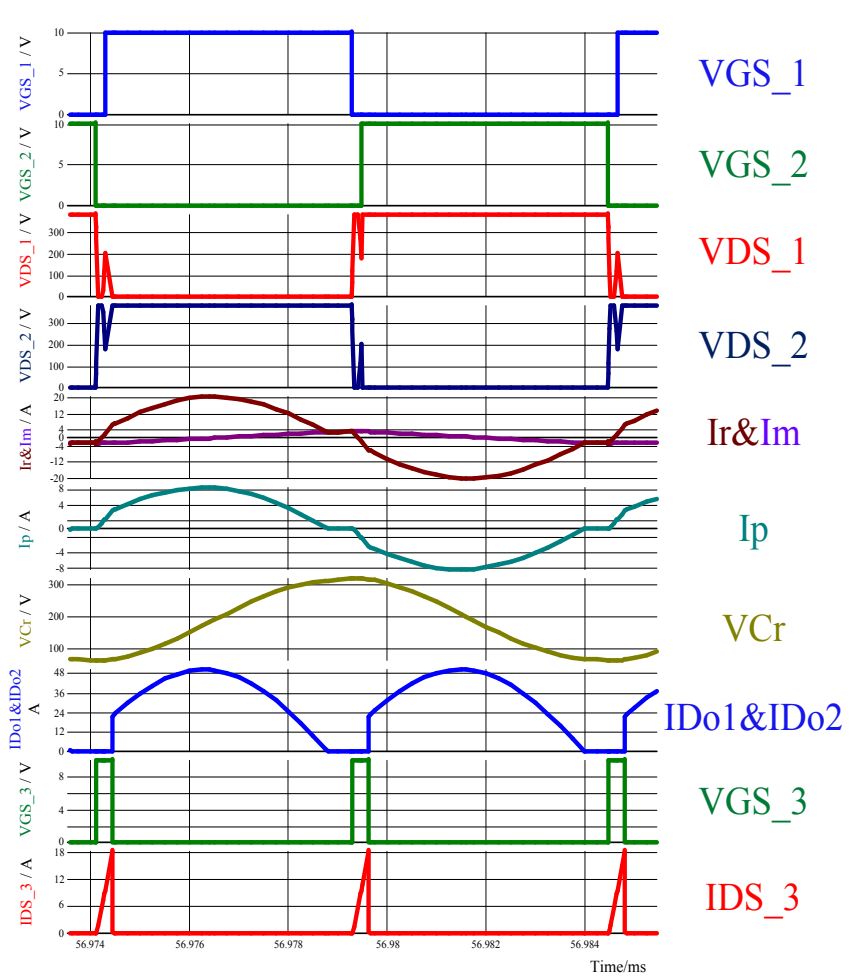

(a)

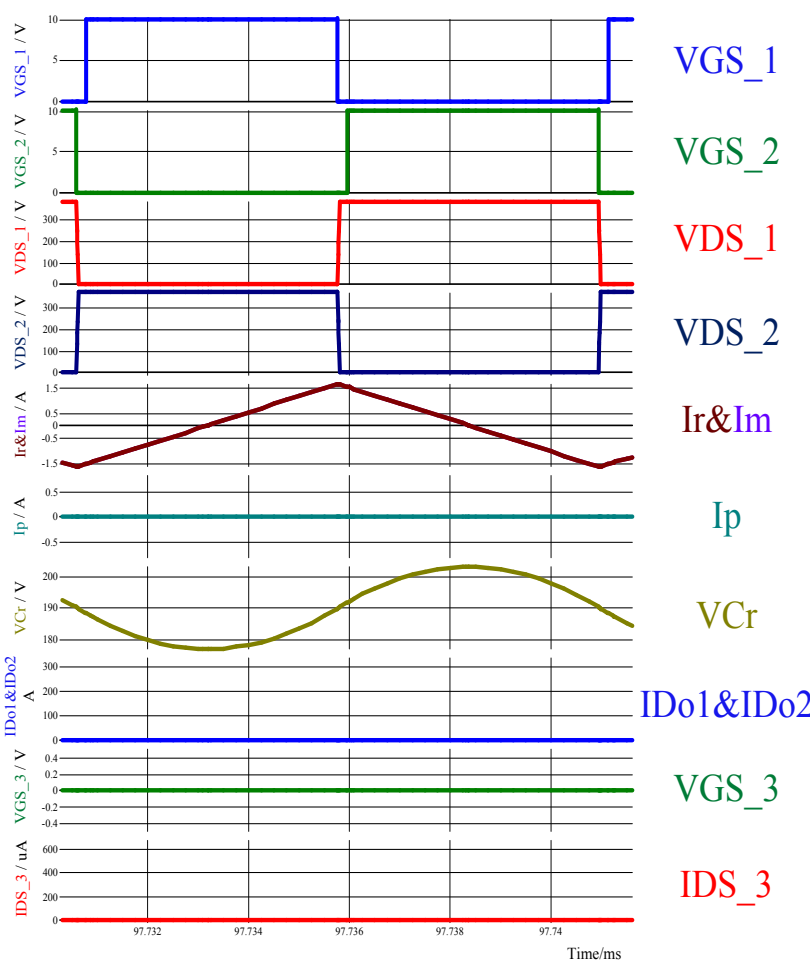

(b)

Figure 24. Simulated waveform for typical LLC control circuit under $1200 \mathrm{~W} / 48 \mathrm{~V}$ : (a) 100\% load; and (b) 0\% load. 
Table 2. Overall power loss at standby.

\begin{tabular}{ccccc}
\hline Specification & \multicolumn{2}{c}{ Type } & Conventional LLC & Novel LLC \\
\hline $480 \mathrm{~W} / 48 \mathrm{~V}$ & MOS-FDP12N50 & $R_{\text {pri }} 0.2 \Omega$ & $2.0305 \mathrm{~W}$ & $1.1846 \mathrm{~W}$ \\
$1200 \mathrm{~W} / 48 \mathrm{~V}$ & MOS-FDA28N50 & $R_{\text {pri }} 0.08 \Omega$ & $10.9608 \mathrm{~W}$ & $5.4568 \mathrm{~W}$ \\
\hline
\end{tabular}

\section{Conclusions}

The purpose of this paper is mainly to focus on renewable energy generation system at standby. A novel control scheme for LLC converters is introduced to optimize switching loss and improve standby efficiency. Features between typical LLC circuit and proposed LLC control circuit get analyzed in detail. From SIMPLIS simulation results and standby power loss evaluation, some overall conclusions can be derived as follows:

(1) Systems with proposed control schemes achieve optimal standby power consumptions.

(2) Even though the magnetizing inductance remains unchanged, the resonant inductance is permitted with a relatively small design, bringing advantages such as smaller volumes of magnetic components and improving power density.

(3) This system can also enhance current gain and operate in a wide input range. The hold-up time increases, which reduces capacitance size and improves power density; additionally, operating range of wind generators gets improved.

(4) The control loop at system input and output side is independent, and therefore, isolation between control circuits is naturally accomplished.

\section{Acknowledgments}

This work was supported by the Ministry of Science and Technology of Taiwan under Contracts 103-3113-E-194-003 and 104-3113-E-194-003. The authors would like to thank Leadtrend Technology Corp. for the support on chip fabrication, measurement, and verifications.

\section{Author Contributions}

Both of the authors played important roles during the design of standby efficiency improvement and partially wrote the paper. Ming-Chang Tsou ran the simulation and Ming-Tse Kuo reviewed and revised the manuscript.

\section{Conflicts of Interest}

The authors declare no conflict of interest.

\section{References}

1. Giraud, F.; Salameh, Z.M. Steady-state performance of a grid-connected rooftop hybrid wind-photovoltaic power system with battery storage. IEEE Trans. Energy Convers. 2001, 16, 1-7. 
2. Nehrir, M.H.; LaMeres, B.J.; Venkataramanan, G.; Gerez, V.; Alvarado, L.A. Performance Evaluation of Stand-Alone Wind/Photovoltaic Genera System. In Proceedings of the IEEE Power Engineering Society Summer Meeting, Edmonton, AB, Canada, 18-22 July 1999; Volume 1, pp. 555-559.

3. Park, S.J.; Kang, B.B.; Yoon, J.P.; Cha, I.S.; Lim, J.Y. A Study on the Stand-Alone Operating or Photovoltaic/Wind Power Hybrid Generation System. In Proceedings of the IEEE 35th Annual Power Electronics Specialists Conference, PESC 04, Aachen, Germany, 20-25 June 2004; Volume 3, pp. 2095-2099.

4. Dou, X.; Quan, X.; Wu, Z.; Hu, M.; Sun, J.; Yang, K.; Xu, M. Improved control strategy for microgrid ultracapacitor energy storage systems. Energies 2014, 7, 8095-8115.

5. Drouilhet, S.; Muljadi, E.; Holz, R.; Gevorgian, V. Optimizing Small Wind Turbine Performance in Battery Charging Applications; NREL/TP-441-7808; National Renewable Energy Laboratory (NREL): Golden, CO, USA, 1995.

6. Lee, F.C.; Barbosa, P.; Xu, P.; Zhang, J.; Yang, B.; Canales, F. Topologies and design considerations for distributed power system applications. Proc. IEEE 2001, 89, 939-950.

7. Krishna, R.A.; Dutt, A.A. LLC Resonant Converter with Renewable Energy Source for Low Voltage Application. In Proceedings of the 2011 International Conference on Signal Processing, Communication, Computing and Networking Technologies (ICSCCN), Thuckafay, India, 21-22 July 2011; pp. 383-388.

8. Yang, B.; Lee, F.C.; Zhang, A.J.; Huang, G.S. LLC Resonant Converter for Front End DC/DC Conversion. In Proceedings of the Seventeenth Annual IEEE Applied Power Electronics Conference and Exposition, APEC 2002, Dallas, TX, USA, 10-14 March 2002; Volume 2, pp. 1108-1112.

9. Yang, B. Topology Investigation for Front End DC/DC Power Conversion for Distributed Power. Ph.D. Thesis, Virginia Tech, Blacksburg, VA, USA, 2003.

10. Fang, Y.; Xu, D.; Zhang, Y.; Gao, F.; Zhu, L.; Chen, Y. Standby Mode Control Circuit Design of LLC Resonant Converter. In Proceedings of the IEEE Power Electronics Specialists Conference, PESC 2007, Orlando, FL, USA, 17-21 June 2007; pp. 726-730.

11. Ye, Y.; Yan, C.; Zeng, J.; Ying, J. A Novel Light Load Solution for LLC Series Resonant Converter. In Proceedings of the 29th International Telecommunications Energy Conference, INTELEC 2007, Rome, Italy, 30 September-4 October 2007; pp. 61-65.

12. Jung, J.-H.; Kwon, J.-G. Theoretical Analysis and Optimal Design of LLC Resonant Converter. In Proceedings of the 2007 European Conference on Power Electronics and Applications, Aalborg, Denmark, 2-5 September 2007; pp. 1-10.

13. Cheng, C.A.; Chen, H.W.; Chang, E.C.; Yen, C.H.; Lin, K.J. Efficiency Study for a 150W LLC Resonant Converter. In Proceedings of the International Conference on Power Electronics and Drive Systems, PEDS 2009, Taipei, Taiwan, 2-5 November 2009; pp. 1261-1265.

14. Kim, B.-C.; Park, K.-B.; Kim, C.-E.; Lee, B.-H.; Moon, G.-W. LLC resonant converter with adaptive link-voltage variation for a high-power-density adapter. IEEE Trans. Power Electron. 2010, 25, 2248-2252.

(C) 2015 by the authors; licensee MDPI, Basel, Switzerland. This article is an open access article distributed under the terms and conditions of the Creative Commons Attribution license (http://creativecommons.org/licenses/by/4.0/). 